Article

\title{
Saccharomyces Cerevisiae Var. Boulardii: Valuable Probiotic Starter for Craft Beer Production
}

\author{
Joaquín Mulero-Cerezo ${ }^{1}$, Álvaro Briz-Redón ${ }^{2}$ and Ángel Serrano-Aroca $1, *(1)$ \\ 1 Facultad de Veterinaria y Ciencias Experimentales, Universidad Católica de Valencia San Vicente Mártir, \\ c/Guillem de Castro 94, 46001 Valencia, Spain \\ 2 Departament d'Estadística i Investigació Operativa, Facultat de Matemàtiques, Universitat de València, \\ c/Dr. Moliner, 50, 46100 Burjassot, València, Spain \\ * Correspondence: angel.serrano@ucv.es; Tel.: +34-963637412 (ext. 5256)
}

Received: 10 June 2019; Accepted: 6 August 2019; Published: 8 August 2019

check for updates

\section{Featured Application: Craft Beer Production.}

\begin{abstract}
The use of probiotic starters remaining viable in unpasteurized and unfiltered beers could significantly increase health benefits. Here, the probiotic Saccharomyces cerevisiae var. boulardii $\left(S c_{b}\right)$ and a commercial Saccharomyces cerevisiae $(S c)$ strain, which is commonly employed in the brewing industry, are compared as single starters. The healthy value of the produced beers and growth performance in a laboratory bioreactor are analysed by determining antioxidant activity, phenolic content and profile, alcohol, biomass growth modelling by the logistic and Gompertz equations, biovolume estimation from 2D microscopy images, and yeast viability after fermentation. Thus, in this study, the craft beer produced with the probiotic yeast possessed higher antioxidant activity, lower alcohol content, similar sensory attributes, much higher yeast viability and more acidification, which is very desirable to reduce contamination risks at large-scale production. Furthermore, $S c_{b}$ exhibited faster growth in the bioreactor culture and larger cell volumes than $S c$, which increases the probiotic volume of the final craft beer.
\end{abstract}

Keywords: craft beer; Saccharomyces cerevisiae var. boulardii; Saccharomyces cerevisiae; antioxidant activity; polyphenols; biovolume; yeast viability; probiotics; bioreactor; Logistic and Gompertz equations

\section{Introduction}

The most important brewer's yeasts are mostly part of the genus Saccharomyces. Thus, ale and lager yeasts belong to Saccharomyces cerevisiae $(S c)$ and Saccharomyces pastorianus, respectively [1]. S. pastorianus is a hybrid of Sc and Saccharomyces eubayanus. Sc is one of the most important brewing yeast species utilised for ale beer production due to its tolerance to alcohol [2], growth and fermentation rate on an industrial scale [3]. Saccharomyces cerevisiae var. boulardii $\left(S c_{b}\right)$ is another popular yeast species that was isolated from fruit in Indochina and has been utilised as a remedy for diarrhea since $1950[4,5] . S c_{b}$ has shown a capacity to prevent travellers' diarrhea usually caused by bacteria such as Escherichia coli and Salmonella sp. [6,7].

Probiotics are microorganisms used as food supplements that in a correct dosage are potentially beneficial for human health, especially for the intestinal microbial balance [8]. Gastrointestinal microbiote imbalances can develop into several disorders, such as diarrhea under antibiotic treatment, ulcers, inflammatory bowel diseases or irritable bowel syndrome [9]. $S c_{b}$ is the only yeast species with probiotic properties able to keep gastrointestinal conditions at a suitable health level. $S c_{b}$, in particular, has been very effective against Clostridium difficile in the prevention and treatment of antibiotic 
associated diarrhea $[10,11]$ and may help to eradicate Helicobacter pylori [12]. In fact, the $S c_{b}$ yeast is now commercially available in most countries globally.

$S c_{b}$ shows enhanced ability for pseudohyphal switching upon nitrogen limitation and increased resistance to acidic $\mathrm{pH}$, which are not correlated with increased adherence to epithelial cells or transit through mouse gut [13]. However, a recent genetic comparative study of $5 S c_{b}$ against 145 Sc yeast strains has revealed the presence of two genes, HXT11 and HXT9, in Sc, which are not present in $S c_{b}$ [14]. The absence of these genes has been related to greater resistance against several antifungals, such as cycloheximide, sulfometuron methyl and 4-nitroquinoline-N-oxide [15]. Other genetic particularities that have been reported for $S c_{b}$ include the absence of ASP3 genes involved in asparagine degradation [16] and the abundant repetition of Flocculation (FLO) genes, which could explain the ability of $S c_{b}$ to adhere to the intestinal epithelium [17,18].

The optimal growth temperature of $S c_{b}$ is $37^{\circ} \mathrm{C}$ and thus it can reach very high gastrointestinal tract (GT) concentrations in a very short period [19]. In addition, it possesses the capacity to inhibit the growth, adherence and invasion of multiple pathogens such C. difficile [20], E. coli [21], and Candida albicans [22], both in in vitro and in vivo conditions to the epithelial layer of the GT.

In recent years, there has been a worldwide increase in the consumer interest in craft beers, which are unpasteurized, unfiltered and without additional nitrogen or carbon dioxide pressure [23]. Even though there are many controversial studies about the beneficial effects of beer consumption on human health, epidemiological studies have shown that beer has positive effects on cardiovascular protection inhibiting atherosclerosis, decreasing the content of serum low-density lipoprotein cholesterol and triglycerides, by acting as an in vivo free radical scavenger [24,25].

This alcoholic beverage is usually mainly composed of four basic ingredients: water, hops, malt, and brewer's yeast, as well as non-nutrient components such as phenolic compounds [26]. Brewer's yeast strains are facultative anaerobes and this ability supports their property as an important industrial microorganism [27]. Phenolic compounds are present in vegetable foods such as malt and hops [28].

The use of $S c_{b}$ as a mixed starter with $S c$ for craft beer [29] or as a single starter for alcohol-free beer production [30] has been proposed recently. However, these results were preliminary and warrant further investigation in order to compare $S c_{b}$ as a single starter with other yeast strains such as S. cerevisiae Safale S-04, which is commonly employed in the brewing industry and especially selected for this purpose, in terms of health benefits (antioxidant activity, total phenolic content, polyphenol profile, alcohol formation) and probiotic value-added (biomass growth, cell volume and yeast viability after fermentation).

\section{Materials and Methods}

\subsection{Materials}

Methanol (HPLC grade), formic acid, Folin-Ciocalteu's phenol reagent and sodium carbonate was acquired from Panreac (Barcelona, Spain). The 2,2-Diphenyl-1-picrylhydrazyl (DPPH) reagent, methanol (99.8\%) and some polyphenol standard patterns (phloroglucinol, protocatechuic acid, epicatechin, quercetin, myricetin, ferulic acid, p-coumaric acid, rutin, gentisic, caffeic and catechin) were purchased from Sigma-Aldrich (Steinheim, Switzerland). Chlorogenic acid and vanillic acid polyphenol patterns were provided by HWI (Ruelzheim, Germany) and Fluka Analytical (Steinheim, Switzerland) respectively.

S. cerevisiae Safale S-04, hereafter referred to as SF-04, was provided by the Fermentis Division of S. I. Lesaffre (Lille, France). Saccharomyces cerevisiae var. boulardii CECT 1474 was purchased from the Spanish Type Culture Collection (CECT, Valencia, Spain). $S c$ and $S c_{b}$ were suspended in distilled water to be grown in Sabouraud Glucose Agar with Chloramphenicol (SGAC, Sigma-Aldrich, Steinheim, Switzerland) solid medium plates at their optimal culture temperatures, 27 and $37^{\circ} \mathrm{C}$, respectively, for isolation. After that, $S c$ and $S c_{b}$ were grown in yeast peptone dextrose (YPD) broth (Sigma-Aldrich, Steinheim, Switzerland) with an orbital shaker-incubator for $48 \mathrm{~h}$ also at 27 and $37^{\circ} \mathrm{C}$, respectively. Finally, 1-mL aliquots of pure cultures were subsequently frozen at $-80^{\circ} \mathrm{C}$. 


\subsection{Wort Preparation and Beer Fermentation Procedure}

The wort was prepared with a commercial Connoisseur Indian Pale Ale (IPA) bitter Kit (Muntons, UK) containing 100\% hopped malt extract. This beer style was chosen because it is very popular in the craft-beer market [31]. For each yeast strain, $1.56 \mathrm{~kg}$ of this extract was mixed with $3.5 \mathrm{~L}$ of boiling drinking water. Then, pure cold drinking water was added to that mixture to reach a total volume of $20 \mathrm{~L}$ under vigorous mixing in a sterilized plastic fermenter. Subsequently, $5 \mathrm{~mL}$ of pure yeast culture at a concentration of $8 \times 10^{6}$ cell/mL was inoculated into this mixture. Finally, the fermenter was covered with a lid to maintain a sterile internal environment and was fermented in anaerobic conditions at ambient temperature $\left(24 \pm 1^{\circ} \mathrm{C}\right)$ for 9 days. This temperature was maintained within the fermentation temperature range recommended by the SF-04 strain producer (Fermentis). After fermentation the beer was bottled and stored at $4 \pm 0.5^{\circ} \mathrm{C}$.

The main analytical characteristics of the initial wort $\left(\mathrm{pH},{ }^{\circ} \mathrm{Plato}\right.$, density, and free amino nitrogen (FAN)) were measured with $310-\mathrm{mL}$ aliquots in order to ensure its reproducibility. The FAN of the wort was determined according to the Sörensen analytical method [32]. Sugar consumption (in ${ }^{\circ} \mathrm{Plato}$ ) and $\mathrm{pH}$ were measured as a function of time during the fermentation process. These fermentations were performed 3 times in order to ensure reproducibility.

\subsection{Polyphenols and Antioxidant Activity}

The total phenolic content (TPC) measurement is usually combined with the stable free radical 2,2-Diphenyl-1-picrylhydrazyl (DPPH) technique in order to estimate also the total antioxidant activity [33]. Thus, an UV/VIS Nanocolor UV0245 spectrophotometer (Macherey-Nagel, Düren, Germany) was used at different wavelengths (765 and $515 \mathrm{~nm}$, respectively) to determine the TPC and antioxidant activity of the craft beers after 9 days fermentation. For each experiment, aliquots of $1 \mathrm{~mL}$ were taken from the fermented beers to remove $\mathrm{CO}_{2}$ gas by sonication for $10 \mathrm{~min}$ and then passed through a $0.2-\mu \mathrm{m}$ filter.

\subsubsection{Total Phenolic Content}

TPC of the produced craft beers was determined by the Folin-Ciocalteu method [34]. A volume of $100 \mu \mathrm{L}$ of the filtered and sonicated beer aliquots were introduced into a test tube with $8.4 \mathrm{~mL}$ of water and $0.5 \mathrm{~mL}$ of Folin-Ciocalteu reagent. The mixture was left to react for $5 \mathrm{~min}$ in the dark. Then, $1 \mathrm{~mL}$ of sodium carbonate $(20 \%, v / v)$ was added to this mixture, stirred, and left in the dark at $27 \pm 1{ }^{\circ} \mathrm{C}$ for $60 \mathrm{~min}$. The TPC values were then determined by measuring the absorbance at $765 \mathrm{~nm}$ and applying the linear regression equation $(y=0.0009 x+0.0093)$, expressed in equivalents of gallic acid $(G A)$ per $L$ of beer (mg GA/L). These measurements were performed 6 times for each beer to ensure accurate results as both mean and standard deviation.

\subsubsection{DPPH Scavenging Activity}

The antioxidant activity was determined by the DPPH method [35]. A volume of $100 \mu \mathrm{L}$ of the filtered and sonicated beer aliquots was placed in a test tube with $5 \mathrm{~mL}$ of mixture containing $0.005 \mathrm{~g}$ of DPPH in $200 \mathrm{~mL}$ of methanol. This mixture was well-stirred and left in the dark at $27 \pm 1^{\circ} \mathrm{C}$ for $20 \mathrm{~min}$. The absorbance of this mixture $\left(A_{\text {sample }}\right)$ and that of a control sample $\left(A_{0}\right)$ with only methanol was then measured at $515 \mathrm{~nm}$. Finally, the antioxidant activity of each craft beer could be determined by applying the radical scavenging activity (RSA) Equation (1).

$$
\operatorname{RSA}(\%)=100\left(\frac{A_{0}-A_{\text {sample }}}{A_{0}}\right)
$$

These measurements were performed 6 times with each beer in order to guarantee the reproducibility of the results. 


\subsubsection{Polyphenol Profiles}

The polyphenol profiles of the beers produced with the two yeast strains ( $S c$ and $S c_{b}$ ) were determined by chromatographic analysis after 9 days fermentation. Beer aliquots of $1 \mathrm{~mL}$ were centrifuged, passed through $0.20-\mu \mathrm{m}$ filters and then sonicated to remove carbon dioxide prior to analysis.

High-performance liquid chromatography coupled with a L-2455 diode array detector (HPLC/DAD) was performed with a HPLC Hitachi 890-0442 (Tokyo, Japan) apparatus equipped with L-2300 column oven, L-2200U autosampler and L-2130 pump, connected to the EZChromElite ${ }^{\mathrm{TM}}$ software. The separation was performed with a LiChrospher ${ }^{\circledR} 100$ RP-18 (Darmstadt, Germany) reverse phase column $(250 \mathrm{~mm} \times 4.6 \mathrm{~mm}, 5 \mu \mathrm{m})$ at $27^{\circ} \mathrm{C}$. A gradient system with two mobile phases was used: water with $0.1 \%$ formic acid (eluent A) and methanol (eluent B). The flow rate was $1.0 \mathrm{~mL} / \mathrm{min}$ with an injection volume of $60 \mu \mathrm{L}$ beer. The elution conditions applied consisted of $0-4 \mathrm{~min}$ of isocratic $10 \% \mathrm{~B}, 4-15 \mathrm{~min}$ linear gradient from $10 \%$ to $50 \% \mathrm{~B}$ and $15-30 \mathrm{~min}$ of isocratic $50 \% \mathrm{~B}$. HPLC/DAD chromatographs for each craft beer were taken at 270, 324 and $373 \mathrm{~nm}$.

Thirteen commercial polyphenol patterns usually found in beer [36] were used to identify and quantify the polyphenol profile in each beer sample. These polyphenols patterns were previously analysed to determine their retention times at the corresponding wavelengths (see Table 1) and the calibration lines employed to transform peak areas into concentrations.

Table 1. Retention times and wavelengths for the polyphenols standard patterns.

\begin{tabular}{ccc}
\hline Polyphenol & Retention Time (min) & Wavelength (nm) \\
\hline Phloroglucinol & 4.01 & \\
Catequin & 12.66 & 270 \\
Vanillic acid & 14.29 & \\
Epicatechin & 15.14 & \\
Protocatechuic acid & 18.49 & \\
Rutin & 19.20 & 324 \\
\hline Gentisic acid & 11.86 & \\
Chlorogenic acid & 13.81 & \\
Caffeic acid & 14.63 & 373 \\
p-coumaric acid & 16.84 & \\
Ferulic acid & 17.41 & \\
\hline Myricetin & 20.48 & \\
Quercetin & 24.18 & \\
\hline
\end{tabular}

The stock solutions with the polyphenol standards were prepared and diluted with methanol to the appropriate concentration in the range of $0.5-250 \mathrm{mg} / \mathrm{L}$. Thus, 6 concentrations of each polyphenol pattern were prepared and injected in triplicate to construct the calibration lines (with $R^{2}>0.999$ ) by plotting peak area versus concentration for each polyphenol.

These HPLC/DAD measurements were carried out in triplicate to be reported as mean and standard deviations.

\subsection{Bioreactor Culture}

The bioreactor cultures were treated in an autoclave $\left(121^{\circ}\right.$ for $\left.15 \mathrm{~min}\right)$ and performed in a $2-\mathrm{L}$ Biostat A bench-top bioreactor (Sartorius, Frankfurt, Germany) containing 1 L of Sabouraud Glucose with Chloramphenicol liquid medium. This medium was prepared with $40 \mathrm{~g} / \mathrm{L}$ of D-(+)-Glucose ( $\geq 99.5 \%$, Sigma-Aldrich, Steinheim, Switzerland), $17.4 \mathrm{~g} / \mathrm{L}$ of nutrient broth containing $5 \mathrm{~g} / \mathrm{L}$ of peptone (Thermo Fisher Scientific (Oxoid), Berkshire, UK), $0.05 \mathrm{~g} / \mathrm{L}$ chloramphenicol ( $\geq 98 \%$, Sigma-Aldrich, Steinheim, Switzerland) and $25 \mathrm{~g} / \mathrm{L}$ of Miller's LB Broth with $10 \mathrm{~g} / \mathrm{L}$ of tryptone (Sigma-Aldrich, Steinheim, Switzerland). 
Bioreactor cultures were conducted in anaerobic conditions with a constant stirring speed of $100 \mathrm{rpm}$ to ensure homogeneous mixing and low foam formation. Acidification was studied by continuous $\mathrm{pH}$ monitoring during $85 \mathrm{~h}$ of incubation time. Inoculation was performed with $5 \mathrm{~mL}$ of the yeast culture with an average concentration of $10^{6}$ cells $/ \mathrm{mL}$. The experiments were carried out at $24 \pm 1{ }^{\circ} \mathrm{C}$ in order to study cell growth at the same temperature to that used for the craft beer fermentations.

Yeast growth was analysed in the bioreactor culture by turbidimetry [37]. Thus, continuous spectrophotometric measurements with 10-mL aliquots were performed at $630 \mathrm{~nm}$ every $1 \mathrm{~h}$ for $50 \mathrm{~h}$. These bioreactor culture determinations were carried out in triplicate in order to ensure reproducibility.

\subsection{Growth Analysis and Modelling}

Absorbance measurements at $630 \mathrm{~nm}$ (turbidimetry) as a function of time (t) were modelled by the Gompertz equation [38] and logistic function [39] (Equations (2) and (3), respectively) in order to study cell growth trends. In these models, there are three parameters: the maximum attainable value $(K)$, the growth rate $(r)$ and the $\mathrm{x}$-axis displacement $(a)$.

$$
\begin{gathered}
\gamma(t)=k e^{-a \cdot e^{-r \cdot t}} \\
\sigma(t)=\frac{K}{1+e^{-r \cdot(t-a)}}
\end{gathered}
$$

Experimental growth curves were also modelled by a particular Gompertz and logistic model (Equations (4) and (5), respectively) capable of treating data differently depending on the type of yeast employed. These mathematical models have only one parameter $(r)$ and include an indicator variable (I) with a value of 0 for $S c$ and 1 for $S c_{b}$. These equations also include three new parameters $\left(s_{1}, s_{2}\right.$ and $s_{3}$ ) to estimate the possible growth level of each yeast species by modifying $K, r$ and $a$ parameters as a function of time $(t)$.

$$
\begin{aligned}
\gamma_{b}(t) & =\left(K+s_{1} I\right) e^{-\left(a+s_{3} I\right) e^{-\left(r+s_{2} I\right) t}} \\
\sigma_{b}(t) & =\frac{K+s_{1} I}{1+e^{-\left(r+s_{2} I\right)\left(t-\left(a+s_{3} I\right)\right)}}
\end{aligned}
$$

The $n l s$ (nonlinear least squares) function of the R programming language [40] was used to perform these mathematical modelling studies [41].

\subsection{Biovolume Estimation}

Equations for the estimation of cell volume (biovolume) for a wide range of microorganisms have become increasingly precise and powerful, especially since the introduction of allometric models [42]. Although laser and digital confocal microscopy can acquire 3D images, these techniques are time-consuming and expensive. In this regard, digital two-dimensional images acquired with an optical microscope have been recently proposed as a very promising alternative low-cost technique for biovolume mathematical estimation [43,44]. Thus, approximately 100 microscopy images of individual randomly selected cells (colonies were not considered) were taken for each yeast strain with a BA410 optical microscope (Motic, Kowloon, Hong Kong) provided with a Motic 580 5.0 MP camera and Motic Image Plus 3.0 software. These microscopy images were analysed with the aid of the $R$ EBImage package [45]. Thus, the cell volumes were estimated from the 2D cell images by applying Equation (6) [43]. In this equation, $A$ represents the estimated area of the cell cross-section in pixels according to the EBImage functionalities, $d$ is the major axis of the ellipse that better fits their section and $E$ is the exact area of the ellipse. In addition, the $\sqrt{\frac{A}{E}}$ term is a correction factor to obtain a more realistic approximation of the real cell volume. 


$$
V=\frac{2}{3} A d \sqrt{\frac{A}{E}}
$$

This method produces an average error below $1 \%$ even when some complex-shaped cells are analysed [42]. Therefore, since the analysed shapes of this study are quite simple (elliptical), the error must be almost negligible.

The biovolume differences found between $S c$ and $S c_{b}$ was confirmed with the use of a unilateral $t$-test [46]. The Kolmogorov-Smirnov test [47] was also performed in order to reject the hypothesis that the two samples are drawn from the same continuous distribution.

\subsection{Yeast Viability}

Cell viability of the yeasts present in the craft beers was evaluated by the colony counting method [48] after 45 days ( 9 days fermentation and 36 days stored at $4{ }^{\circ} \mathrm{C}$ ) to determine the colony forming units (CFUs) per $\mathrm{mL}$ of viable cells in each craft beer. Thus, serial dilutions of the fermented craft beers were prepared in YPD. Then, $100 \mu \mathrm{L}$ of each cell dilution was spread onto SGAC plates and grown at $37^{\circ} \mathrm{C}$ for $72 \mathrm{~h}$. This experiment was performed 3 times in order to ensure reproducibility.

\subsection{Specific Gravity and Alcohol Concentration}

The specific gravities of the wort $\left(\rho_{\text {woort }}\right)$ and the fermented beers $\left(\rho_{\text {beer }}\right)$ were determined with an EasyDens meter (Anton-Paar GmbH, Austria, Graz). It is well-known that an accurate estimate of alcohol content can be determined from these specific gravity values [49]. However, $\rho_{\text {beer }}$ is an apparent value and its real value ( $\left.\rho_{\text {beer }}^{\prime}\right)$ must be estimated with the Equation (7).

$$
\rho_{\text {beer }}^{\prime}=0.1948 \times O E+0.8052 \times \rho_{\text {beer }}
$$

Thus, the alcohol percentage by weight $\left(A B W_{t}\right)$, as grams of alcohol per $100 \mathrm{~g}$ of beer, can be obtained by applying Equation (8) with $\rho_{\text {wort }}$ and $\rho^{\prime}$ beer expressed in degrees Plato:

$$
A B W_{t}=\frac{\rho_{\text {wort }}-\rho_{\text {beer }}^{\prime}}{2.0665-\left(1.0665 \times \frac{\rho_{\text {wort }}}{100}\right)}
$$

The alcohol percentage by volume of the produced beers $(A B V)$ can be deduced with a correction to account for the specific gravity of the beers $\left(\rho_{\text {beer }}\right.$ in $\left.\mathrm{g} / \mathrm{cm}^{3}\right)$ in the following Equation (9).

$$
A B V=\frac{A B W_{t} \times \rho_{\text {beer }}}{0.7907}
$$

\subsection{Sensory Evaluation}

The analysis for the content of main volatile compounds has recently shown that the use of $S c_{b}$ in combination with $S c$ as mixed starter does not negatively affect beer aroma [29]. Nonetheless, a deep sensory evaluation of attributes of the beers produced with $S c_{b}$ and $S c$ as single starters after 9 days of fermentation was performed by a panel of 10 trained experts. The descriptive assessment of attributes (appearance, aroma, flavor and bitterness) was carried out on a scale from 1 (extremely dislike attribute) to 9 (extremely like attribute).

\subsection{Software}

The R programming language (3.4.1 version, R Development Core Team, Vienna, Austria) [40] was used to perform the modelling and statistical analysis of the experimental results. Thus, the ggplot2 (plot creation), imputeTS (time series missing values imputation), nls (non-linear least squares), and EBImage (image analysis) R packages were selected for this study. 
The statistical analysis (ANOVA and Tukey's post hoc test) of the fermentation measurements ( $\mathrm{pH}$ and $\left.{ }^{\circ} \mathrm{Plato}\right)$, polyphenol concentrations and sensory evaluations were performed with SPSS22 at a significance level of $p<0.05$.

\section{Results}

\subsection{Physicochemical Parameters During Fermentation}

The main analytical characteristics of the initial unfermented wort were: $\mathrm{pH} 6.7 \pm 0.2,5.9 \pm 0.6$ ${ }^{\circ}$ Plato and $150.8 \pm 8.2 \mathrm{mg} / \mathrm{L}$ of FAN. It is of note that the $\mathrm{pH}$ of the wort is higher than usual due to the type of tap water used for its preparation. Thus, this water was collected from Valencia, Spain, and contains a high $\mathrm{CaCO}_{3}$ content. Since the goal of this study was focused on producing a craft beer with healthy added value, a low initial Plato value ensured a lower alcohol formation. Figure 1 shows the ${ }^{\circ}$ Plato and $\mathrm{pH}$ measurements during the nine days of wort fermentation for the two yeast strains.

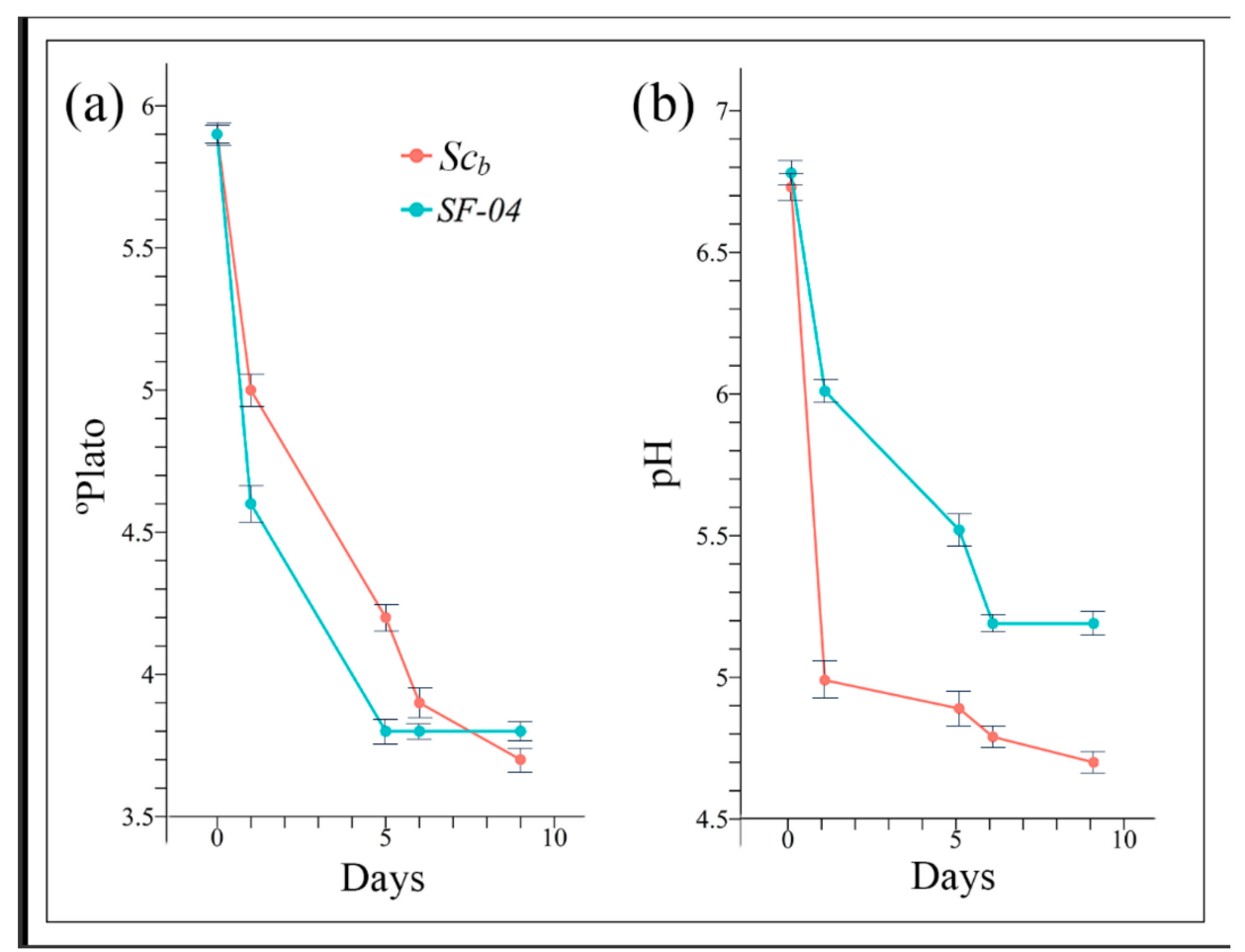

Figure 1. Plato degrees (a) and $\mathrm{pH}(\mathbf{b})$ evolution during beer fermentation using the Saccharomyces cerevisiae var. boulardii $\left(S c_{b}\right)$ and Saccharomyces cerevisiae (SF-04) strains as single starters. Results shown as mean \pm standard deviation.

Figure 1a shows that the Plato degree trend followed a similar pattern independently from the type of yeast strain utilised. However, the $\mathrm{pH}$ achieved with $S c_{b}$ in the fermented beer was statistically significantly $(p<0.05)$ lower than with $S c$ during the whole fermentation process (see Figure $1 \mathrm{~b}$ ). This decrease of $\mathrm{pH}$ as a function of time was expected with both beers due to organic acid formation during fermentation [50]. Furthermore, FAN, which possess buffering capacity [51], is consumed by yeast during fermentation [52]. The stronger acidification achieved with this probiotic yeast during fermentation considerably reduces the contamination risk [53] and thus renders a more promising possibility for the production of this craft beer on a large scale. Furthermore, in a brewery, it has been reported that acidification may improve foam stability with a more well-rounded taste and increased shelf life in comparison to the non-acidified beer [54]. 


\subsection{Antioxidant Activity and Total Phenolic Content After Fermentation}

Phenolic compounds mostly come from both the malt and hops in beer [55] and will decrease from wort due to its degradation depending on the type of fermentation conditions [56]. However, in this study, the beers were produced with similar amounts and types of $100 \%$ hopped malt extract, employing the same experimental conditions. Thus, the TPC measurements determined by the Folin-Ciocalteu method showed similar results for both $S c_{b}$ and $S c$ species (see Table 2), within the experimental uncertainty expected.

However, the DPPH technique (RSA) revealed a significant increase of antioxidant activity for the craft beer produced with the probiotic $S c_{b}$ yeast, in good agreement with previous results of co-fermentation of $S c_{b}$ with $S c$ [29]. This increase of antioxidant activity of the beer fermented with $S c_{b}$ could be attributed to the presence of metabolites secreted by the $S c_{b}$ species such as proteins [57-61] with high antioxidant activity [62].

Table 2. Total phenolic content (TPC) determined by the Folin-Ciocalteu method and expressed in mg of gallic acid (GA) per L, antioxidant activity (RSA) obtained by the stable free radical 2,2-Diphenyl-1-picrylhydrazyl (DPPH) technique and expressed in \% by Equation (1), wort density $\left(\varrho_{\text {wort }}\right)$, beer density $\left(\varrho_{\text {beer }}\right)$, alcohol percentage by weight $\left(\mathrm{ABW}_{\mathrm{t}}\right)$ and by volume $(\mathrm{ABV})$ of the craft beer fermented with Saccharomyces cerevisiae (Sc) and Saccharomyces cerevisiae var. boulardii (SF-04) yeast strains. Results of TPC and RSA shown as mean \pm standard deviation. * Statistically significant differences $(p<0.05)$.

\begin{tabular}{|c|c|c|c|c|c|c|}
\hline Yeast Strain & $\begin{array}{c}\text { TPC } \\
\text { (mg GA/L) }\end{array}$ & $\begin{array}{l}\text { RSA } \\
(\%)\end{array}$ & $\begin{array}{c}\rho_{\text {wort }} \\
\left(\mathrm{kg} / \mathrm{m}^{3}\right)\end{array}$ & $\begin{array}{c}\rho_{\text {beer }} \\
\left(\mathrm{kg} / \mathrm{m}^{3}\right)\end{array}$ & $\begin{array}{c}A B W_{t} \\
(\%)\end{array}$ & $\begin{array}{c}A B V \\
(\%)\end{array}$ \\
\hline SF-04 & $0.1597 \pm 0.0373$ & $11.51 \pm 0.36$ & 1028 & 1008 & 1.87 & 2.39 \\
\hline$S c_{b}$ & $0.1545 \pm 0.0192$ & $16.80 \pm 0.31$ * & 1028 & 1014 & 1.29 & 1.65 \\
\hline
\end{tabular}

Table 2 shows that the alcohol content by weight $\left(A B W_{t}\right)$ and by volume $(A B V)$, determined with $\rho_{\text {wort }}$ and $\rho_{\text {beer }}$ in Equations (7)-(9), is lower in the beer produced with $S c_{b}$ than in the commercial beer.

\subsection{HPLC/DAD Analysis After Fermentation}

Even though the Folin-Ciocalteu (F-C) assay [34] is a standardized method to determine the phenolic content of food products and dietary supplements [63], an accurate HPLC/DAD analysis of the polyphenol types and contents was performed to confirm these results. Thus, the results of this analysis showed that, from the 13 polyphenol patterns, 6 peaks exhibited significant concentrations (see Figure 2).

These results confirm that both beers exhibit a similar polyphenol profile with a few polyphenols (phloroglucinol, catequin and ferulic acid) showing slightly higher concentrations in the beer produced with $S c$ (see Figure 2). Therefore, the higher antioxidant activity found in the beer produced with $S c_{b}$ could be attributed to antioxidant compounds other than polyphenols, secreted by the probiotic yeast. Thus, for example, the $S c_{b}$ yeast was found to produce $(1 \rightarrow 3)-\beta$-D-glucan, which exhibits antioxidant and immunomodulation properties very suitable for anti-infective and antitumor therapy [64]. In addition, literature reports also suggest that $S c_{b}$ produces certain antioxidant metabolites responsible for its anti-inflammatory activity $[58,60]$. 


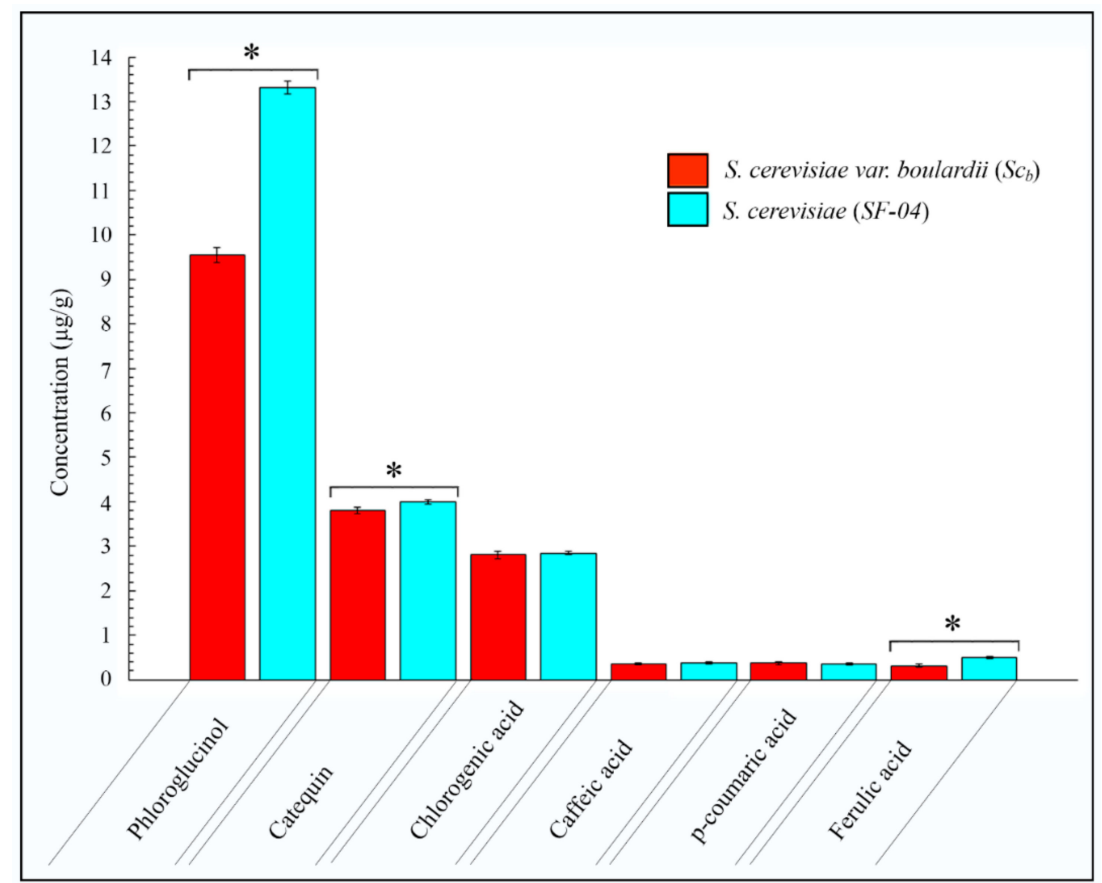

Figure 2. High performance liquid chromatograpy results for the beers fermented with the Saccharomyces cerevisiae var. boulardii $\left(S_{C b}\right)$ and Saccharomyces cerevisiae (SF-04) yeast strains. The polyphenols were detected at three different wavelengths $(270 \mathrm{~nm}, 324 \mathrm{~nm}$ and $373 \mathrm{~nm})$. Results shown as mean \pm standard deviation. ${ }^{*}$ Statistically significant difference of polyphenol concentrations $(p<0.05)$.

\subsection{Yeast Growth Analysis in Bioreactor Culture}

The use of the logistic function $[39,65]$ and the Gompertz model $[66,67]$ to represent the cell growth of several types of microorganisms as a function of time has been proved to be successful in many studies during the last decade. Since craft beers are unpasteurized and unfiltered, it is important to study cell growth at the same fermentation temperature $\left(24 \pm 1{ }^{\circ} \mathrm{C}\right)$ and anaerobic conditions in monitored bench-top bioreactors. Figure 3 shows the experimental turbidimetric results obtained during $50 \mathrm{~h}$ incubation and the mathematical growth modelling performed by logistic and Gompertz equations.

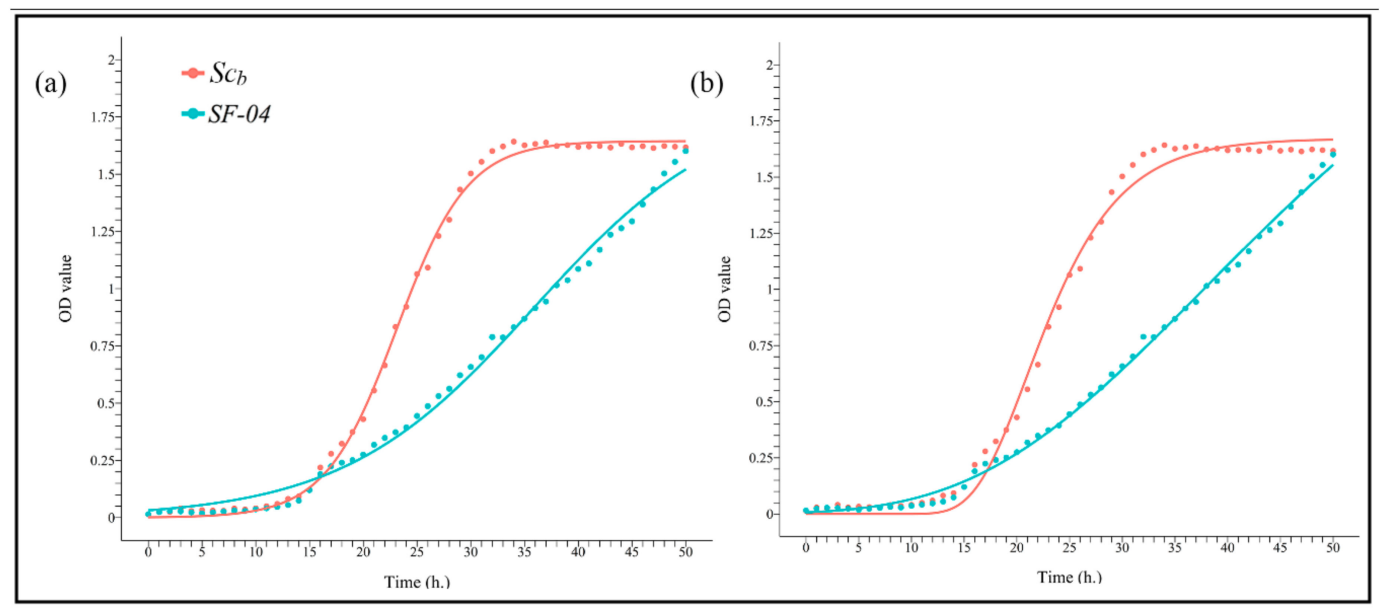

Figure 3. Experimental values (points) and mathematical modelling (continuous lines) of absorbance measurements at $630 \mathrm{~nm}$ as a function of time for the Saccharomyces cerevisiae (SF-04) and Saccharomyces cerevisiae var. boulardii $\left(S_{C b}\right)$ strains cultured in batch bioreactor in anaerobic conditions at $24 \pm 1{ }^{\circ} \mathrm{C}$. Mathematical modelling was performed with the logistic (a) and Gompertz (b) equations. 
The estimated values of $K, a$ and $r$ obtained from the modelling of the turbidimetric measurements as a function of time are shown in Table 3 for the logistic and Gompertz models, respectively.

Table 3. Parameter estimates of $k, a, r$ and their errors for the logistic and Gompertz models applied to the absorbance measurements at $630 \mathrm{~nm}$ for the Saccharomyces cerevisiae (SF-04) and Saccharomyces cerevisiae var. boulardii $\left(S_{C b}\right)$ strains cultured in batch bioreactors at $24 \pm 1^{\circ} \mathrm{C}$ for $50 \mathrm{~h}$. All these results are statistically significant $(p<0.05)$.

\begin{tabular}{cccccccc}
\hline Yeast Strain & $\boldsymbol{K}$ & Error & \multicolumn{1}{c}{$\boldsymbol{a}$} & Error & $\boldsymbol{r}$ & Error & Model \\
\hline SF-04 & 1.832 & 0.066 & 35.858 & 0.799 & 0.113 & 0.005 & \multirow{2}{*}{ Logistic } \\
$S c_{b}$ & 1.644 & 0.008 & 23.092 & 0.093 & 0.302 & 0.007 & \\
\hline SF-04 & 2.719 & 0.143 & 5.960 & 0.179 & 0.047 & 0.002 & Gompertz \\
$S c_{b}$ & 1.671 & 0.016 & 69.873 & 14.079 & 0.203 & 0.009 & \\
\hline
\end{tabular}

Both mathematical models clearly show superior growth rates for $S c_{b}$ (see $r$ values in Table 3). In addition, Equations (4) and (5) confirmed the increased growth rates achieved by $S c_{b}$ in comparison to $S c$. Indeed, these equations estimated significant $s_{2}$ parameter values ( $p$-value $\left.<2 \times 10^{-16}\right)$ for $S c_{b}$ and $S c$ respectively, corresponding to different growth rates for both yeast species. A similar level of significance was found for the $s_{3}$ parameter, which estimates the likely different growth levels for both yeast species by modifying the $a$ parameter. Thus, this result confirms a different growth curve temporization because the $a$ parameter is related to the displacement along the temporal $\mathrm{x}$-axis. However, the $s_{1}$ parameter was not significant for both Gompertz and logistic models, suggesting a similar saturation value for both species during a growth time cycle of $50 \mathrm{~h}$.

A previous study also showed higher growth rates for $S c_{b}$ (Floratil ${ }^{\circledR}$ ) in comparison with $S c$ (W303) at 30 and $37^{\circ} \mathrm{C}$ [68]. Therefore, $S c_{b}$ grows faster than $S c$ at the same fermentation temperature of this study $\left(24 \pm 1^{\circ} \mathrm{C}\right)$ and at the body temperature $\left(37^{\circ} \mathrm{C}\right)$.

\subsection{Physicochemical Parameters During Bioreactor Culture}

Figure 4 shows acidification as a function of time produced by $S c_{b}$ and $S c$ during bioreactor culture at $24 \pm 1{ }^{\circ} \mathrm{C}$.

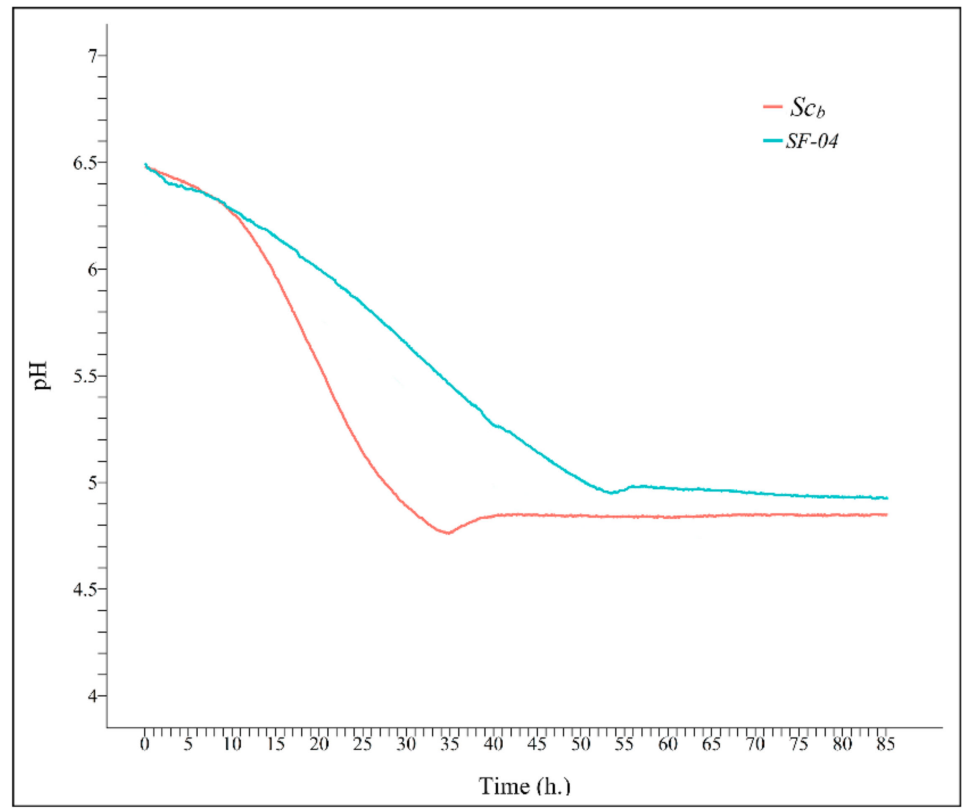

Figure 4. Monitored $\mathrm{pH}$ values as a function of time for the Saccharomyces cerevisiae (SF-04) and Saccharomyces cerevisiae var. boulardii $\left(S_{C b}\right)$ strains in bioreactor batch culture at $24 \pm 1{ }^{\circ} \mathrm{C}$. 
These $\mathrm{pH}$ results are in accordance with the lower $\mathrm{pH}$ values achieved with $S c_{b}$ during fermentation (Figure $1 \mathrm{~b}$ ). Moreover, the specific gravity (in ${ }^{\circ}$ Plato) for the $S c$ and $S c_{b}$ yeasts were also very similar at the beginning $\left(9.2 \pm 0.2\right.$ and $9.2 \pm 0.1^{\circ}$ Plato, respectively) and at the end $\left(4.0 \pm 0.1\right.$ and $3.7 \pm 0.2^{\circ}$ Plato, respectively) of fermentation during bioreactor culture (Figure 1a).

\subsection{Yeast Biovolumes}

Figure 5 shows the biovolume value distribution results (in $\mu \mathrm{m}^{3}$ ) estimated from the 2D optical microscopy images for both yeast strains. The biovolumes were normalised and scaled to $[0,1]$ to be comparable. Thus, the $S c_{b}$ cells exhibited higher average values than the $S c$ cells. The biovolumes of the $S c_{b}$ and $S c$ were $129.27 \pm 32.90$ and $70.72 \pm 24.58 \mu \mathrm{m}^{3}$, respectively. This result of biovolume of $S c$ is in good accordance with those cell volumes shown for this type of yeast [69,70]. However, as far as we know, the biovolumes of $S c_{b}$ have never been reported previously in the literature. The higher biovolume of $S c_{b}$ was confirmed with the use of a unilateral $t$-test, which yielded a $p$-value below $4.578 \times 10^{-10}$ and thus allowed rejection of the hypothesis that both species possess equal mean biovolumes. In addition, the Kolmogorov-Smirnov test showed a $p$-value below $7.985 \times 10^{-11}$, which led to rejection of the hypothesis that the two samples are drawn from the same continuous distribution.

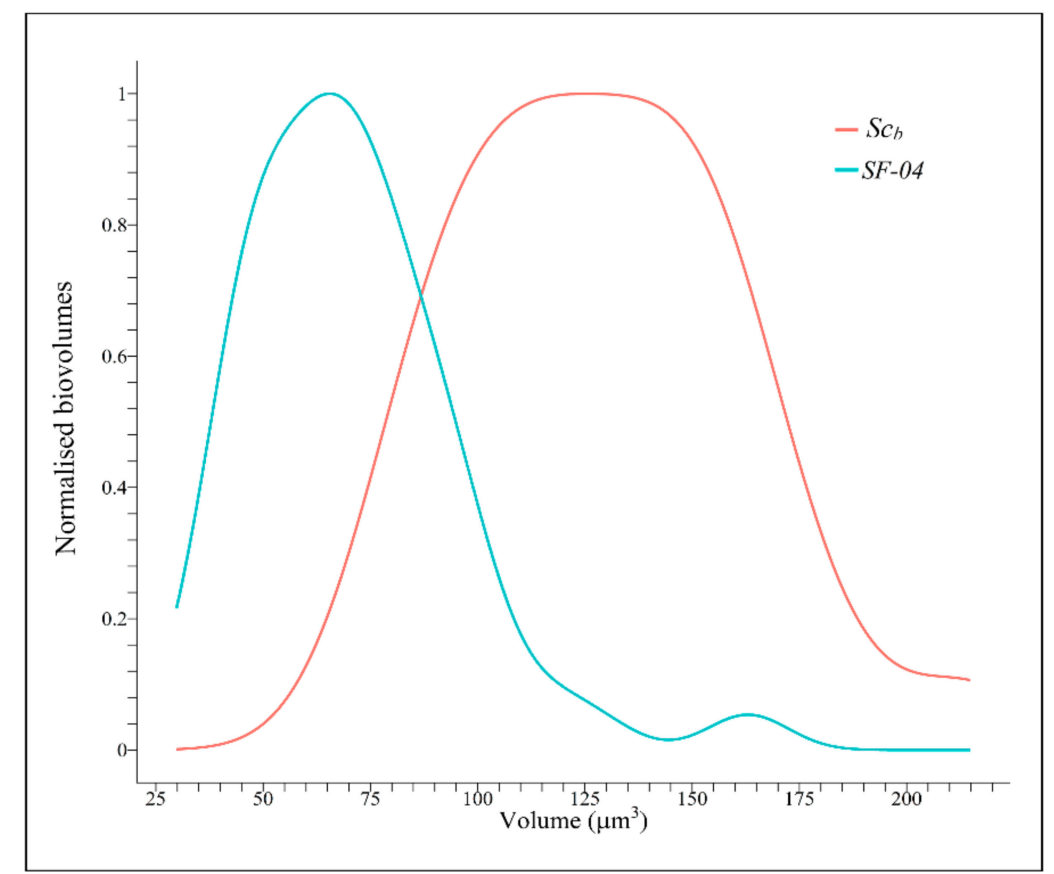

Figure 5. Normalised cell volume (biovolume) distribution values estimated for the Saccharomyces cerevisiae var. boulardii $\left(S_{C b}\right)$ and Saccharomyces cerevisiae (SF-04) strains.

\subsection{Yeast Viability in the Craft Beers}

Since craft beers are largely unpasteurized and unfiltered, and their probiotic value depends on the amount of viable probiotic cells present in the beer after fermentation, yeast viability was measured in the craft beers by the colony counting method. Thus, Figure 6 shows the yeast viability results obtained for each craft beer after 45 days. 


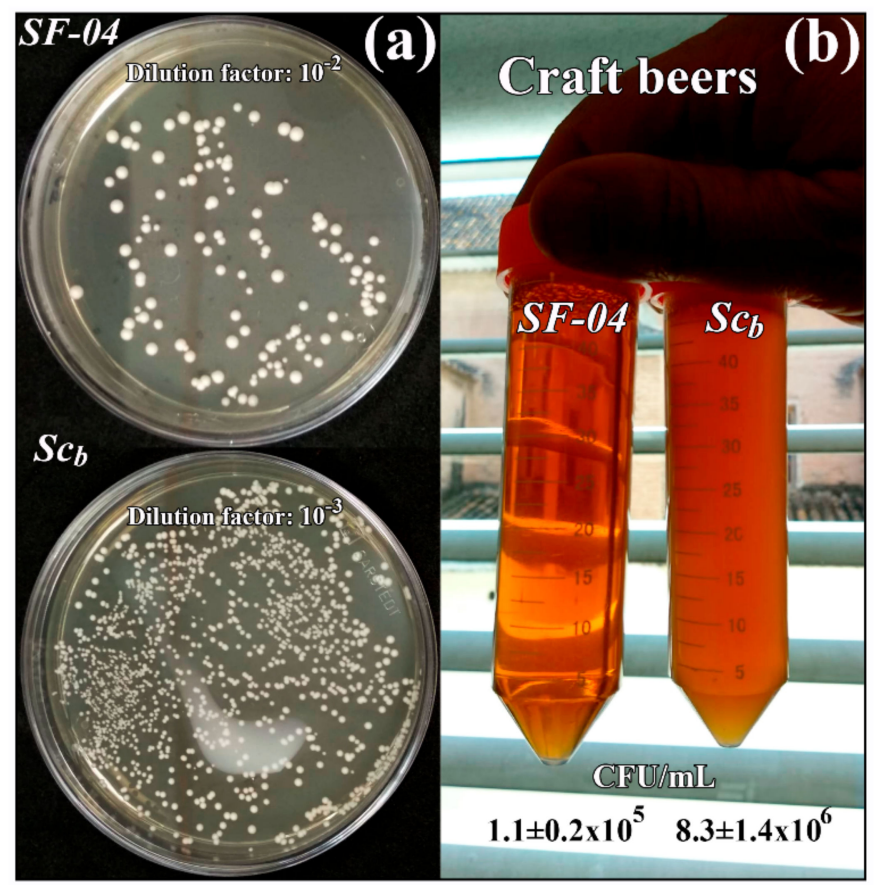

Figure 6. Yeast viability (a) of the Saccharomyces cerevisiae var. boulardii $\left(S c_{b}\right)$ and Saccharomyces cerevisiae (SF-04) strains in the craft beers (b) determined by the colony counting method after 45 days. The number of colonies, which are the number of viable microorganisms (expressed in $\mathrm{CFU} / \mathrm{mL}$ ) in the craft beers and representative plate images of the viable yeast colonies with a dilution factor $10^{-2}$ and $10^{-3}$ for SF-04 and $S_{C b}$, respectively, are shown.

These results clearly show higher viability of $S_{b}$ than $S c$ (see CFU/mL and the transparency of the Falcon tubes in Figure 6b) after fermentation, which is ideal for producing a craft beer containing viable probiotic cells.

Table 4 shows that both yeasts produce craft beers with similar sensory attributes. Thus, these results are in good agreement with previous studies demonstrating that the use of $S c_{b}$ does not negatively affect beer aroma [29] and produces craft beer with acceptable sensory attributes [30].

Table 4. Sensory evaluation results for the beers produced with the Saccharomyces cerevisiae (SF-04) and Saccharomyces cerevisiae var. boulardii $\left(S c_{b}\right)$ strains. Scale from 1 (extremely dislike attribute) to 9 (extremely like attribute). Results expressed as mean \pm standard deviation. No significant differences $(p<0.05)$ between row and column values were found.

\begin{tabular}{ccccc}
\hline Yeast Strain & Appearance & Aroma & Flavor & Bitterness \\
\hline SF-04 & $6.25 \pm 1.03$ & $6.12 \pm 0.99$ & $5.87 \pm 1.13$ & $4.75 \pm 1.04$ \\
$S c_{b}$ & $6.50 \pm 1.41$ & $5.62 \pm 1.51$ & $5.37 \pm 1.30$ & $5.25 \pm 1.58$ \\
\hline
\end{tabular}

Therefore, all the results obtained in this and previous studies render $S c_{b}$ as a very promising yeast for craft beer production with increased health benefits as a result of large-scale production. However, the results of the present study have been determined at a small scale and thus cannot be directly extended to large-scale production.

\section{Conclusions}

In this study, probiotic Saccharomyces cerevisiae var. boulardii as a single yeast starter has been shown to produce craft beer with higher antioxidant activity, lower alcohol content, similar sensory attributes and higher yeast viability after 45 days than that produced by a commercial Saccharomyces cerevisiae strain commonly used in the brewery industry. Furthermore, it produced higher acidification in bioreactor 
culture and also during fermentation, which is desirable to avoid contamination risks during large-scale production. Since polyphenols come mostly from hops and malt in beer, both craft beers resulted in a similar phenolic content and polyphenol profile. $S c_{b}$ showed faster growth than $S c$ in the batch bioreactor culture at $24{ }^{\circ} \mathrm{C}$ and the microscopy analysis revealed superior cell volumes for the $S c_{b}$ yeast, which increases the probiotic volume in the final craft beer. However, these results were obtained at the 20-L scale and thus more research should be performed before considering this promising beverage for large-scale industrial production.

Author Contributions: J.M.-C. and Á.S.-A. conceived the idea of this study. J.M.-C. performed all the experiments. Á.B.-R. performed the mathematical analysis and contributed to the manuscript text and figures of this part. Á.S.-A. got financial support, designed the experimental planning, supervised, analysed and discussed the data results, and prepared the draft and final manuscript text and figures.

Funding: This research was funded by the Universidad Católica de Valencia San Vicente Mártir through the PRUCV2018-231-001 and PRUCV 2019-231-003 grants (awarded to Á.S.-A).

Acknowledgments: The authors would like to acknowledge the Universidad Católica de Valencia San Vicente Mártir for the financial support, the Biotechnologist Laura Salinero Martín for her help with the bioreactor batch cultures, and both Carolina Padrón and Mariola Belda for their help with the HPLC/DAD measurements.

Conflicts of Interest: The authors declare no conflict of interest.

\section{References}

1. Kurtzman, C.P.; Fell, J.W.; Boekhout, T. The Yeasts: A Taxonomic Study; Elsevier: Amsterdam, The Netherlands, 2011; ISBN 9780080931272.

2. Ding, J.; Huang, X.; Zhang, L.; Zhao, N.; Yang, D.; Zhang, K. Tolerance and stress response to ethanol in the yeast Saccharomyces cerevisiae. Appl. Microbiol. Biotechnol. 2009, 85, 253-263. [CrossRef] [PubMed]

3. Lodolo, E.J.; Kock, J.L.F.; Axcell, B.C.; Brooks, M. The yeast Saccharomyces cerevisiae-The main character in beer brewing. In FEMS Yeast Research; Wiley/Blackwell: Hoboken, NJ, USA, 2008; Volume 8, pp. 1018-1036.

4. McCullough, M.J.; Clemons, K.V.; Mccusker, J.H.; Stevens, D.A. Species identification and virulence attributes of Saccharomyces boulardii. J. Clin. Microbiol. 1998, 36, 2613-2617. [PubMed]

5. Hancox, L.R.; Le Bon, M.; Richards, P.J.; Guillou, D.; Dodd, C.E.R.; Mellits, K.H. Effect of a single dose of Saccharomyces cerevisiae var. boulardii on the occurrence of porcine neonatal diarrhoea. Animal 2015, 9, 1756-1759. [CrossRef] [PubMed]

6. Leggat, P.A.; Goldsmid, J.M. Others the returned traveller with diarrhoea. Aust. Fam. Physician 2007, 36, 322.

7. McFarland, L.V. Meta-analysis of probiotics for the prevention of traveler's diarrhea. Travel Med. Infect. Dis. 2007, 5, 97-105. [CrossRef] [PubMed]

8. Moslehi-Jenabian, S.; Pedersen, L.L.; Jespersen, L. Beneficial effects of probiotic and food borne yeasts on human health. Nutrients 2010, 2, 449-473. [CrossRef] [PubMed]

9. Czerucka, D.; Piche, T.; Rampal, P. Review article: Yeast as probiotics-Saccharomyces boulardii. Aliment. Pharmacol. Ther. 2007, 26, 767-778. [CrossRef] [PubMed]

10. Kabbani, T.A.; Pallav, K.; Dowd, S.E.; Villafuerte-Galvez, J.; Vanga, R.R.; Castillo, N.E.; Hansen, J.; Dennis, M.; Leffler, D.A.; Kelly, C.P. Prospective randomized controlled study on the effects of Saccharomyces boulardii CNCM I-745 and amoxicillin-clavulanate or the combination on the gut microbiota of healthy volunteers. Gut Microbes 2017, 8, 17-32. [CrossRef] [PubMed]

11. Surawicz, C.M. Treatment of recurrent Clostridium difficile-associated disease. Nat. Clin. Pract. Gastroenterol. Hepatol. 2004, 1, 32-38. [CrossRef]

12. Greenhill, C. Probiotic helps to eradicate H. pylori. Nat. Rev. Gastroenterol. Hepatol. 2010, 7, 362. [CrossRef]

13. Edwards-Ingram, L.; Gitsham, P.; Burton, N.; Warhurst, G.; Clarke, I.; Hoyle, D.; Oliver, S.G.; Stateva, L. Genotypic and physiological characterization of Saccharomyces boulardii, the probiotic strain of Saccharomyces cerevisiae. Appl. Environ. Microbiol. 2007, 73, 2458-2467. [CrossRef] [PubMed]

14. Khatri, I.; Tomar, R.; Ganesan, K.; Prasad, G.S.; Subramanian, S. Complete genome sequence and comparative genomics of the probiotic yeast Saccharomyces boulardii. Sci. Rep. 2017, 7, 371. [CrossRef] [PubMed] 
15. Nourani, A.; Wesolowski-Louvel, M.; Delaveau, T.; Jacq, C.; Delahodde, A. Multiple-drug-resistance phenomenon in the yeast Saccharomyces cerevisiae: Involvement of two hexose transporters. Mol. Cell. Biol. 1997, 17, 5453-5460. [CrossRef] [PubMed]

16. League, G.P.; Slot, J.C.; Rokas, A. The ASP3 locus in Saccharomyces cerevisiae originated by horizontal gene transfer from Wickerhamomyces. FEMS Yeast Res. 2012, 12, 859-863. [CrossRef] [PubMed]

17. Verstrepen, K.J.; Klis, F.M. Flocculation, adhesion and biofilm formation in yeasts. Mol. Microbiol. 2006, 60, 5-15. [CrossRef] [PubMed]

18. Stratford, M. Genetic aspects of yeast flocculation: In particular, the role of FLO genes in the flocculation of Saccharomyces cerevisiae. Colloids Sur. B Biointerfaces 1994, 2, 151-158. [CrossRef]

19. Karen, M.; Yuksel, O.; Akyürek, N.; Ofluoğlu, E.; Çağlar, K.; Şahin, T.T.; Paşaoğlu, H.; Memiş, L.; Akyürek, N.; Bostanci, H. Probiotic Agent Saccharomyces boulardii Reduces the Incidenceof Lung Injury in Acute Necrotizing Pancreatitis Induced Rats. J. Surg. Res. 2010, 160, 139-144. [CrossRef]

20. Surawicz, C.M.; McFarland, L.V.; Greenberg, R.N.; Rubin, M.; Fekety, R.; Mulligan, M.E.; Garcia, R.J.; Brandmarker, S.; Bowen, K.; Borjal, D.; et al. The Search for a Better Treatment for Recurrent Clostridium difficile Disease: Use of High-Dose Vancomycin Combined with Saccharomyces boulardii. Clin. Infect. Dis. 2000, 31, 1012-1017. [CrossRef]

21. Czerucka, D.; Dahan, S.; Mograbi, B.; Rossi, B.; Rampal, P. Saccharomyces boulardii preserves the barrier function and modulates the signal transduction pathway induced in enteropathogenic Escherichia coli-infected T84 cells. Infect. Immun. 2000, 68, 5998-6004. [CrossRef]

22. Berg, R.; Bernasconi, P.; Fowler, D.; Gautreaux, M. Inhibition of Candida albicans Translocation from the Gastrointestinal Tract of Mice by Oral Administration of Saccharomyces boulardii. J. Infect. Dis. 1993, 168, 1314-1318. [CrossRef]

23. Canonico, L.; Comitini, F.; Ciani, M. Dominance and influence of selected Saccharomyces cerevisiae strains on the analytical profile of craft beer refermentation. J. Inst. Brew. 2014, 120, 262-267. [CrossRef]

24. Granato, D.; Branco, G.F.; de Faria, A.J.; Cruz, A.G. Characterization of Brazilian lager and brown ale beers based on color, phenolic compounds, and antioxidant activity using chemometrics. J. Sci. Food Agric. 2011, 91, 563-571. [CrossRef] [PubMed]

25. De Gaetano, G.; Cerletti, C.; Alkerwi, A.; Iacoviello, L.; Badimon, L.; Costanzo, S.; Pounis, G.; Trevisan, M.; Panico, S.; Stranges, S.; et al. Effects of moderate beer consumption on health and disease: A consensus document. Nutr. Metab. Cardiovasc. Dis. 2016, 26, 443-467. [CrossRef] [PubMed]

26. Esslinger, H.M. Handbook of Brewing: Processes, Technology, Markets; Wiley-VCH: Hoboken, NJ, USA, 2009; ISBN 3527623493.

27. Stewart, G. Saccharomyces species in the Production of Beer. Beverages 2016, 2, 34. [CrossRef]

28. Callemien, D.; Collin, S. Structure, organoleptic properties, quantification methods, and stability of phenolic compounds in beer-A review. Food Rev. Int. 2010, 26, 1-84. [CrossRef]

29. Capece, A.; Romaniello, R.; Pietrafesa, A.; Siesto, G.; Pietrafesa, R.; Zambuto, M.; Romano, P. Use of Saccharomyces cerevisiae var. boulardii in co-fermentations with $S$. cerevisiae for the production of craft beers with potential healthy value-added. Int. J. Food Microbiol. 2018, 284, 22-30. [CrossRef] [PubMed]

30. Senkarcinova, B.; Graça Dias, I.A.; Nespor, J.; Branyik, T. Probiotic alcohol-free beer made with Saccharomyces cerevisiae var. boulardii. LWT 2019, 100, 362-367. [CrossRef]

31. Sanekata, A.; Tanigawa, A.; Takoi, K.; Nakayama, Y.; Tsuchiya, Y. Identification and Characterization of Geranic Acid as a Unique Flavor Compound of Hops (Humulus lupulus L.) Variety Sorachi Ace. J. Agric. Food Chem. 2018, 66, 12285-12295. [CrossRef]

32. Bishop, L.R. The Nitrogen Compounds of Wort And Beer. J. Inst. Brew. 1943, 49, 173-178. [CrossRef]

33. Hseu, Y.-C.; Chang, W.-H.; Chen, C.-S.; Liao, J.-W.; Huang, C.-J.; Lu, F.-J.; Chia, Y.-C.; Hsu, H.-K.; Wu, J.-J.; Yang, H.-L. Antioxidant activities of Toona Sinensis leaves extracts using different antioxidant models. Food Chem. Toxicol. 2008, 46, 105-114. [CrossRef]

34. Julkunen-Tiitto, R. Phenolic Constituents in the Leaves of Northern Willows: Methods for the Analysis of Certain Phenolics. J. Agric. Food Chem. 1985, 33, 213-217. [CrossRef]

35. Ditrych, M.; Kordialik-Bogacka, E.; Czyżowska, A. Antiradical and Reducing Potential of Commercial Beers. Czech. J. Food Sci. 2015, 33. [CrossRef] 
36. Quifer-Rada, P.; Vallverdú-Queralt, A.; Martínez-Huélamo, M.; Chiva-Blanch, G.; Jáuregui, O.; Estruch, R.; Lamuela-Raventós, R. A comprehensive characterisation of beer polyphenols by high resolution mass spectrometry (LC-ESI-LTQ-Orbitrap-MS). Food Chem. 2015, 169, 336-343. [CrossRef]

37. Bovee, T.F.H.; Helsdingen, R.J.R.; Hamers, A.R.M.; van Duursen, M.B.M.; Nielen, M.W.F.; Hoogenboom, R.L.A.P. A new highly specific and robust yeast androgen bioassay for the detection of agonists and antagonists. Anal. Bioanal. Chem. 2007, 389, 1549-1558. [CrossRef]

38. Buchanan, R.L.; Whiting, R.C.; Damert, W.C. When is simple good enough: A comparison of the Gompertz, Baranyi, and three-phase linear models for fitting bacterial growth curves. Food Microbiol. 1997, 14, 313-326. [CrossRef]

39. Kacena, M.A.; Merrell, G.A.; Manfredi, B.; Smith, E.E.; Klaus, D.M.; Todd, P. Bacterial growth in space flight: Logistic growth curve parameters for Escherichia coli and Bacillus subtilis. Appl. Microbiol. Biotechnol. 1999, 51, 229-234. [CrossRef]

40. R Core Team. R Language Definition; R Foundation for Statistical Computing: Vienna, Austria, 2000.

41. Nonlinear Regression Analysis and Its Applications; Bates, D.M.; Watts, D.G. (Eds.) Wiley Series in Probability and Statistics; John Wiley \& Sons, Inc.: Hoboken, NJ, USA, 1988.

42. Saccà, A. Methods for the estimation of the biovolume of microorganisms: A critical review. Limnol. Oceanogr. Methods 2017, 15, 337-348. [CrossRef]

43. Saccà, A. A simple yet accurate method for the estimation of the biovolume of planktonic microorganisms. PLoS ONE 2016, 11, e0151955. [CrossRef]

44. Lenz, M.; Roumans, N.J.T.; Vink, R.G.; Van Baak, M.A.; Mariman, E.C.M.; Arts, I.C.W.; De Kok, T.M.; Ertaylan, G. Estimating real cell size distribution from cross-section microscopy imaging. Bioinformatics 2016, 32, 396-404. [CrossRef]

45. Pau, G.; Fuchs, F.; Sklyar, O.; Boutros, M.; Huber, W. EBImage-an R package for image processing with applications to cellular phenotypes. Bioinformatics 2010, 26, 979-981. [CrossRef]

46. Jekel, J.F.; Katz, D.L.; Elmore, J.G.; Wild, D. Epidemiology, Biostatistics and Preventive Medicine; Elsevier Health Sciences: Amsterdam, The Netherlands, 2007.

47. Massey, F.J. The Kolmogorov-Smirnov Test for Goodness of Fit. J. Am. Stat. Assoc. 1951, 46, 68-78. [CrossRef]

48. Martí, M.; Frígols, B.; Serrano-Aroca, Á. Antimicrobial Characterization of Advanced Materials for Bioengineering Applications. J. Vis. Exp. 2018, e57710. [CrossRef]

49. Spedding, G. Alcohol and Its Measurement. In Brewing Materials and Processes: A Practical Approach to Beer Excellence; Academic Press: Cambridge, MA, USA, 2016; pp. 123-149.

50. Erkan, H.; Çelik, S.; Bilgi, B.; Köksel, H. A new approach for the utilization of barley in food products: Barley tarhana. Food Chem. 2006, 97, 12-18. [CrossRef]

51. Agu, R.C.; Palmer, G.H. A reassessment of sorghum for lager-beer brewing. Bioresour. Technol. 1998, 66, 253-261. [CrossRef]

52. Verbelen, P.J.; De Schutter, D.P.; Delvaux, F.; Verstrepen, K.J.; Delvaux, F.R. Immobilized yeast cell systems for continuous fermentation applications. Biotechnol. Lett. 2006, 28, 1515-1525. [CrossRef]

53. Strezov, V.; Evans, T.J. Biomass Processing Technologies; CRC Press: Boca Raton, FL, USA, 2014.

54. Lowe, D.P.; Ulmer, H.M.; Barta, R.C.; Goode, D.L.; Arendt, E.K. Biological acidification of a mash containing $20 \%$ barley using Lactobacillus amylovorus FST 1.1: Its effects on Wort and beer quality. J. Am. Soc. Brew. Chem. 2005, 63, 96-106. [CrossRef]

55. Araki, S.; Kimura, T.; Shimizu, C.; Furusho, S.; Takashio, M.; Shinotsuka, K. Estimation of Antioxidative Activity and its Relationship to Beer Flavor Stability. J. Am. Soc. Brew. Chem. 1999, 57, 34-37. [CrossRef]

56. Montanari, L.; Perretti, G.; Natella, F.; Guidi, A.; Fantozzi, P. Organic and phenolic acids in beer. LWT-Food Sci. Technol. 1999, 32, 535-539. [CrossRef]

57. Pothoulakis, C.; Kelly, C.P.; Joshi, M.A.; Gao, N.; O’Keane, C.J.; Castagliuolo, I.; Lamont, J.T. Saccharomyces boulardii inhibits Clostridium difficile toxin A binding and enterotoxicity in rat ileum. Gastroenterology 1993, 104, 1108-1115. [CrossRef]

58. Castagliuolo, I.; Riegler, M.F.; Valenick, L.; LaMont, J.T.; Pothoulakis, C. Saccharomyces boulardii protease inhibits the effects of Clostridium difficile toxins A and B in human colonic mucosa. Infect. Immun. 1999, 67, 302-307. [CrossRef]

59. Czerucka, D.; Roux, I.; Rampal, P. Saccharomyces boulardii inhibits secretagogue-mediated adenosine 3', 5'-cyclic monophosphate induction in intestinal cells. Gastroenterology 1994, 106, 65-72. [CrossRef] 
60. Castagliuolo, I.; Thomas Lamont, J.; Nikulasson, S.T.; Pothoulakis, C. Saccharomyces boulardii protease inhibits Clostridium difficile toxin A effects in the rat ileum. Infect. Immun. 1996, 64, 5225-5232.

61. Chen, X.; Kokkotou, E.G.; Mustafa, N.; Bhaskar, K.R.; Sougioultzis, S.; O’Brien, M.; Pothoulakis, C.; Kelly, C.P. Saccharomyces boulardii inhibits ERK1/2 mitogen-activated protein kinase activation both in vitro and in vivo and protects against Clostridium difficile toxin A-induced enteritis. J. Biol. Chem. 2006, 281, 24449-24454. [CrossRef]

62. Elias, R.J.; Kellerby, S.S.; Decker, E.A. Antioxidant activity of proteins and peptides. Crit. Rev. Food Sci. Nutr. 2008, 48, 430-441. [CrossRef]

63. Prior, R.L.; Wu, X.; Schaich, K. Standardized methods for the determination of antioxidant capacity and phenolics in foods and dietary supplements. J. Agric. Food Chem. 2005, 53, 4290-4302. [CrossRef]

64. Kogan, G.; Pajtinka, M.; Babincova, M.; Miadokova, E.; Rauko, P.; Slamenova, D.; Korolenko, T.A. Yeast cell wall polysaccharides as antioxidants and antimutagens: Can they fight cancer. In Neoplasma; In Tech: Rijeka, Croatia, 2008; Volume 55, pp. 387-393.

65. Pearl, R.; Slobodkin, L. The Growth of Populations. Q. Rev. Biol. 1976, 51, 6-24. [CrossRef]

66. Chowdhury, B.R.; Chakraborty, R.; Chaudhuri, U.R. Validity of modified Gompertz and Logistic models in predicting cell growth of Pediococcus acidilactici $\mathrm{H}$ during the production of bacteriocin pediocin AcH. J. Food Eng. 2007, 80, 1171-1175. [CrossRef]

67. Chirivella-Martorell, J.; Briz-Redón, Á.; Serrano-Aroca, Á. Modelling of Biomass Concentration, Multi-Wavelength Absorption and Discrimination Method for Seven Important Marine Microalgae Species. Energies 2018, 11, 1089. [CrossRef]

68. Fietto, J.L.; Araújo, R.S.; Valadão, F.N.; Fietto, L.G.; Brandão, R.L.; Neves, M.J.; Gomes, F.C.; Nicoli, J.R.; Castro, I.M. Molecular and physiological comparisons between Saccharomyces cerevisiae and Saccharomyces boulardii. Can. J. Microbiol. 2004, 50, 615-621. [CrossRef]

69. Sun, J.; Yang, J.; Gao, Y.; Xu, D.; Li, D. Reference channel-based microfluidic resistance sensing for single yeast cell volume growth measurement. Microfluid. Nanofluidics 2017, 21, 33. [CrossRef]

70. Wang, J.; Mao, J.; Yang, G.; Zheng, F.; Niu, C.; Li, Y.; Liu, C.; Li, Q. The FKS family genes cause changes in cell wall morphology resulted in regulation of anti-autolytic ability in Saccharomyces cerevisiae. Bioresour. Technol. 2018, 249, 49-56. [CrossRef] 